\title{
Massively Parallel Mesh Generation for Physics Codes
}

\author{
David D. Hardin
}

\author{
RECEIVED \\ JUH 21 1996 \\ OSTI
}

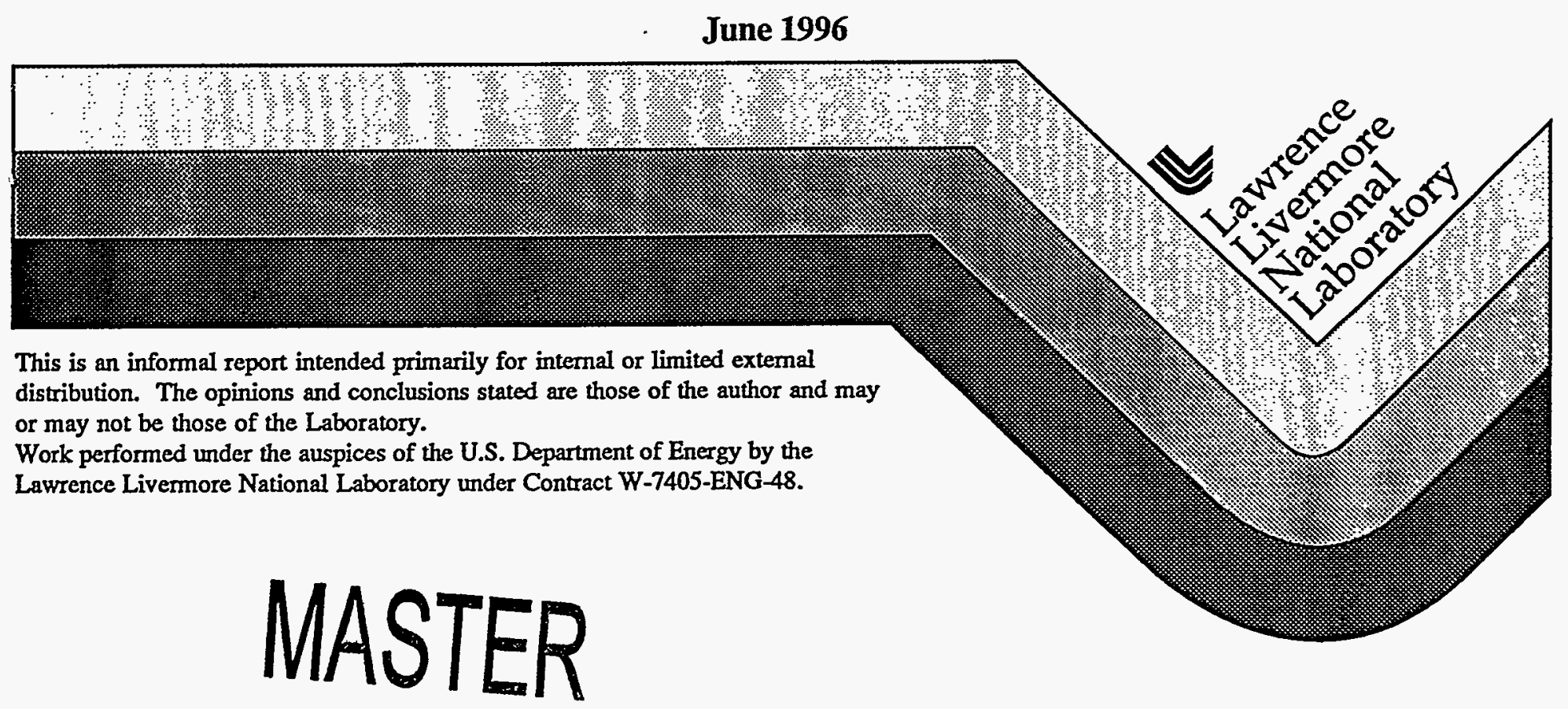




\section{DISCLATMER}

This document was prepared as an account of work sponsored by an agency of the United States Government. Neither the United States Government nor the University of California nor any of their employees, makes any warranty, express or implied, or assumes any legal liability or responsibility for the accuracy, completeness, or usefulness of any information, apparatus, product, or process disclosed, or represents that its use would not infringe privately owned rights. Reference herein to any specific commercial product, process, or service by trade name, trademark, manufacturer, or otherwise, does not necessarily constitute or imply its endorsement, recommendation, or favoring by the United States Government or the University of California. The views and opinions of authors expressed herein do not necessarily state or reflect those of the United States Government or the University of California, and shall not be used for advertising or product endorsement purposes.

This report has been reproduced

directly from the best available copy.

Available to DOE and DOE contractors from the

Office of Scientific and Technical Information

P.O. Box 62, Oak Ridge, TN 37831

Prices available from (615) 576-8401, FTS 626-8401

Available to the public from the

National Technical Information Service

U.S. Department of Commerce

5285 Port Royal Rd.

Springfield, VA 22161 


\section{Massively Parallel Mesh Generation for Physics Codes David D. Hardin}

November 20, 1995

\section{LDRD Project 94-ERP-016}


Massively parallel processors (MPPs) will soon enable realistic 3-D physical modeling of complex objects and systems. Work is planned or presently underway to port many of LLNL's physical modeling codes to MPPs. LLNL's DSI3D electromagnetics code already can solve $40+$ million zone problems on our 256 processor Meiko. However, we lack the software necessary to generate and manipulate the large meshes needed to model many complicated 3-D geometries. State-of-the-art commercial mesh generators run on workstations and have a practical limit of several hundred thousand elements. In the foreseeable future MPPs will solve problems with a billion mesh elements.

The objective of the Parallel Mesh Generation (PMESH) Project is to develop a unique mesh generation system that can construct large 3-D meshes (up to a billion elements) on MPPs. Such a capability will remove a critical roadblock to unleashing the power of MPPs for physical analysis and will put LLNL at the forefront of mesh generation technology. PMESH will "front-end" a variety of LLNL 3-D physics codes, including those in the areas of electromagnetics, structural mechanics, thermal analysis, and hydrodynamics. The DSI3D and DYNA3D codes are already running on MPPs. The primary goal of the PMESH project is to provide the robust generation of large meshes for complicated 3-D geometries through the appropriate distribution of the generation task between the user's workstation and the MPP. Secondary goals are to support the unique features of LLNL physics codes (e.g., unusual elements) and to minimize the user effort required to generate different meshes for the same geometry. PMESH's capabilities are essential because mesh generation is presently a major limiting factor in simulating larger and more complex 3-D geometries. PMESH will significantly enhance LLNL's capabilities in physical simulation by advancing the state-of-the-art in large mesh generation by 2 to 3 orders of magnitude.

During FY'95 we concentrated on attacking a number of problems which relate to making PMESH a practical system for real problems with complex geometries. We significantly extended our graphical user interface (GUI) which now allows the user (1) to rotate and zoom the geometry, (2) to select part edges, faces and volumes in the geometry, and (3) to annotate these entities with attributes that control mesh size, the distribution of the mesh nodes, boundary conditions, and materials.

Unfortunately, we have been plagued by difficulties that reveal the immaturity of commercial Computer-Aided Design (CAD) software. For instance, we have worked on the problem of importing 3-D solid geometry from CAD systems. As Parametric Technology's Pro/ENGINEER is the dominant CAD system at both LLNL and SNL, we have focussed on it. We purchased a commercially-available translator to convert from Pro/ENGINEER's representation of geometry to that of Spatial Technology's ACIS, which is the solid modeling kernel on which PMESH is based. When this translator failed on some of our simplest test problems, we discussed our experiences with Sandia and then acquired a second translator which Sandia has found to be the most successful in its experience. We are presently integrating this product into the PMESH system. Our difficulties are symptomatic of the interchange of 3-D solid models between CAD systems being in its infancy; we hope that the PDES/STEP standard for 3-D model interchange will take hold in the industry during the next year or two. 
As another example, we have encountered problems in ACIS when dealing with simple geometries involving spheres or other bodies of revolution. Problems have come and gone with new releases of ACIS and have required a great deal of attention by the PMESH developers. However, such difficulties are not unique to PMESH; we know of at least three commercially-available mesh generators that cannot mesh a sphere.

These problems should ease as 3-D modeling software matures, but their existence shows that the DOE Laboratories are wise to do in-house mesh generator development. Part of the problem comes from DOE needing to do geometries which are not common in industry. 